\title{
Analysis of low-frequency seismic signals generated during a multiple-iceberg calving event at Jakobshavn Isbra, Greenland
}

\author{
Fabian Walter, ${ }^{1,2,3}$ Jason M. Amundson, ${ }^{4}$ Shad O’Neel, ${ }^{5}$ Martin Truffer, ${ }^{6}$ \\ Mark Fahnestock, ${ }^{6,7}$ and Helen A. Fricker ${ }^{1}$ \\ Received 30 June 2011; revised 25 January 2012; accepted 3 February 2012; published 27 March 2012
}

[1] We investigated seismic signals generated during a large-scale, multiple iceberg calving event that occurred at Jakobshavn Isbræ, Greenland, on 21 August 2009. The event was recorded by a high-rate time-lapse camera and five broadband seismic stations located within a few hundred kilometers of the terminus. During the event two full-glacier-thickness icebergs calved from the grounded (or nearly grounded) terminus and immediately capsized; the second iceberg to calve was two to three times smaller than the first. The individual calving and capsize events were well-correlated with the radiation of low-frequency seismic signals $(<0.1 \mathrm{~Hz})$ dominated by Love and Rayleigh waves. In agreement with regional records from previously published 'glacial earthquakes', these low-frequency seismic signals had maximum power and/or signal-to-noise ratios in the $0.05-0.1 \mathrm{~Hz}$ band. Similarly, full waveform inversions indicate that these signals were also generated by horizontal single forces acting at the glacier terminus. The signals therefore appear to be local manifestations of glacial earthquakes, although the magnitudes of the signals (twice-time integrated force histories) were considerably smaller than previously reported glacial earthquakes. We thus speculate that such earthquakes may be a common, if not pervasive, feature of all full-glacier-thickness calving events from grounded termini. Finally, a key result from our study is that waveform inversions performed on low-frequency, calving-generated seismic signals may have only limited ability to quantitatively estimate mass losses from calving. In particular, the choice of source time function has little impact on the inversion but dramatically changes the earthquake magnitude. Accordingly, in our analysis, it is unclear whether the smaller or larger of the two calving icebergs generated a larger seismic signal.

Citation: Walter, F., J. M. Amundson, S. O’Neel, M. Truffer, M. Fahnestock, and H. A. Fricker (2012), Analysis of low-frequency seismic signals generated during a multiple-iceberg calving event at Jakobshavn Isbræ, Greenland, J. Geophys. Res., 117, F01036, doi:10.1029/2011JF002132.

\section{Introduction}

[2] Dynamic thinning accounts for about half of the mass loss from Greenland [e.g., van den Broeke et al., 2009], nearly all the mass loss from Antarctica [e.g., Rignot et al.,

\footnotetext{
${ }^{1}$ Institute of Geophysics and Planetary Physics, Scripps Institution of Oceanography, University of California, San Diego, La Jolla, California, USA.

${ }^{2}$ Swiss Seismological Service, ETH Zurich, Zurich, Switzerland.

${ }^{3}$ Versuchsanstalt für Wasserbau, Hydrologie und Glaziologie, ETH Zurich, Zurich, Switzerland.

${ }^{4}$ Department of Geophysical Sciences, University of Chicago, Chicago, Illinois, USA.

${ }^{5}$ Alaska Science Center, U.S. Geological Survey, Anchorage, Alaska, USA.

${ }^{6}$ Geophysical Institute, University of Alaska Fairbanks, Fairbanks, Alaska, USA.

${ }^{7}$ Institute for the Study of Earth, Oceans, and Space, University of New Hampshire, Durham, New Hampshire, USA.

Copyright 2012 by the American Geophysical Union. 0148-0227/12/2011JF002132
}

2008] and a substantial, yet undetermined, component of the mass loss from mountain glaciers [Meier et al., 2007]. Some, as of yet unquantified part of this mass loss is attributable to submarine melting, while the rest is due to calving of icebergs. Knowledge of current calving rates and the processes controlling calving are necessary for making accurate assessments of future sea level variability. Much of this knowledge can be gained from time-lapse photography, satellite imagery, and seismology. Seismometers, in particular, are proving to be especially promising, complementary instruments because of their ability both to record calving events at regional [O'Neel et al., 2010] to global distances [Nettles and Ekström, 2010] with excellent temporal resolution, and to provide some measure of the energy released by calving icebergs (thereby giving insights into the physics of calving).

[3] Calving events generate a broad spectrum of unique seismic signals [Qamar, 1988; O'Neel et al., 2007; Amundson et al., 2008; Walter et al., 2010]. These include "glacial earthquakes," which (1) are generated during large-scale 

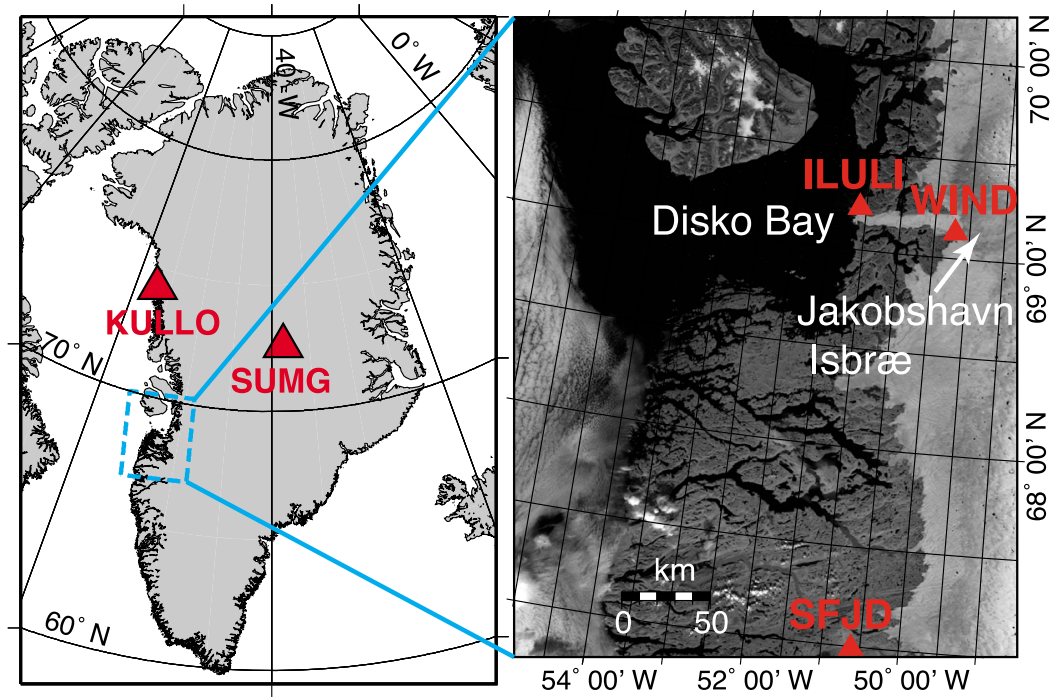

Figure 1. (left) Location of Jakobshavn Isbræ and (right) MODIS image of its terminus, proglacial fjord, and Disko Bay. Seismic stations used in this study are indicated with triangles. The time-lapse camera was collocated with station WIND.

calving events involving capsizing icebergs [Joughin et al., 2008a; Nettles et al., 2008], (2) contain significant energy in the long-period surface wave band (35-150 s period) at teleseismic distances [Ekström et al., 2003, 2006; Nettles and Ekström, 2010], and (3) can be modeled using horizontal single forces that are applied at shallow depths $(<1 \mathrm{~km})$ and are roughly aligned in the direction of glacier flow (with a $180^{\circ}$ ambiguity). Model results furthermore suggest that glacial earthquakes, at least those that are detected globally, have source durations of about $50 \mathrm{~s}$ and magnitudes of $10^{14}$ $\mathrm{kg} \mathrm{m}$ (found by twice time-integrating the calculated force history) [Tsai and Ekström, 2007]. On the basis of these observations and force balance modeling, Tsai et al. [2008] proposed that glacial earthquakes are generated by contact forces between glacier termini and large icebergs as they calve and capsize. For Greenlandic outlet glaciers, this style of calving is commonly observed at fast-flowing outlet glaciers [e.g., Amundson et al., 2010; Nettles and Ekström, 2010].

[4] These previous studies of glacial earthquakes raise several questions about calving seismicity. Are low-frequency seismic signals, such as glacial earthquakes, a ubiquitous phenomenon of calving events involving capsizing icebergs? Are these low-frequency signals indeed generated by iceberg collisions, and if so, does there exist a tractable relationship between the seismic source parameters and iceberg mass and/ or geometry? We begin to address these questions by analyzing regional, broadband seismic data and high-rate time-lapse photography recorded during a multiple-iceberg calving event that occurred at Jakobshavn Isbræ, Greenland (Figure 1), on 21 August 2009.

\section{Data Collection}

[5] The recent calving retreat and flow acceleration of Jakobshavn Isbræ [e.g., Luckman and Murray, 2005; Joughin et al., 2008b] has motivated a variety of instrument deployments near the glacier's terminus. We utilize 10-s imagery from a time-lapse camera and data from collocated broadband station 'WIND' (Guralp CMG3T). Both instruments were located on bedrock within a few kilometers of the terminus (Figures 1 and 2) [see also Amundson et al., 2008, 2010; Lüthi, 2009]. The camera clock was checked daily and reset if it drifted from UTC by more than a couple of seconds. We additionally used data from three permanent broadband seismometers that are incorporated into the new Greenland Ice Sheet Monitoring Network (GLISN, http:// glisn.info/ [Dahl-Jensen et al., 2010]): ILULI (Streckeisen STS-2), KULLO (Streckeisen STS-2), SFJD (Streckeisen STS-1/VBB), and SUMG (Streckeisen STS-2). The station locations are shown in Figure 1. WIND, ILULI and KULLO operated at a sampling frequency of $100 \mathrm{~Hz}$; SFJD and SUMG recorded at $20 \mathrm{~Hz}$. We removed the instrument responses to obtain ground velocity measurements between approximately 0.01 and $10 \mathrm{~Hz}$.

\section{Description of Calving Event}

[6] A large-scale calving event occurred at Jakobshavn Isbræ on 21 August 2009 (Figures 2, 3, and Video S1 of the auxiliary material). ${ }^{1}$ At the time of the calving event the approximately $900 \mathrm{~m}$ thick terminus [Amundson et al., 2008] was grounded, or at least close to being grounded, as is typical for this time of year [Amundson et al., 2010]. Prior to the calving event, which began at 06:56:31 UTC the debris-covered fjord ("ice mélange") showed little motion and emission of seismic energy. The event initiated when a large lamella slid off the ice cliff into the fjord. This was followed by the calving and bottom-out rotation of a fullglacier-thickness iceberg that was approximately 700-1000 m long (across the glacier terminus) and $500 \mathrm{~m}$ wide (in the

\footnotetext{
${ }^{1}$ Auxiliary materials are available in the HTML. doi:10.1029/ 2011 JF002132.
} 

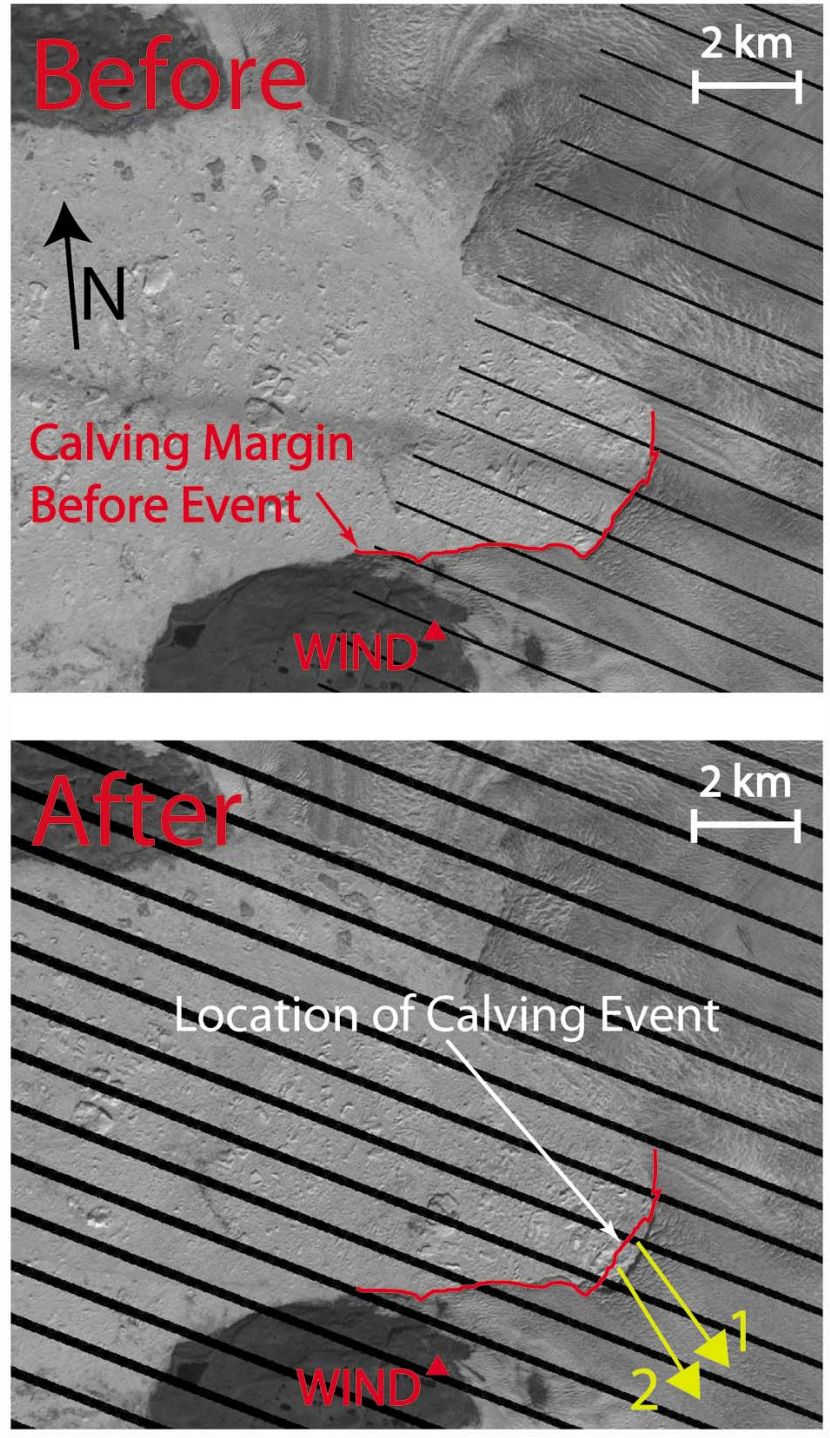

Figure 2. LANDSAT images of Jakobshavn Isbræ's calving front (top) before (14 August 2009) and (bottom) after (23 August 2009) the multiple-iceberg calving event of 21 August 2009 (see also Video S1 of the auxiliary material). The red lines demarcate the pre-calving terminus position. The yellow arrows indicate the single forces as given by the force impulse inversions that generated the first and second low-frequency seismic signals. They are drawn near the approximate location of the calving event, indicated by the LANDSAT and time-lapse images.

glacier flow direction). As the iceberg rotated, it pushed the proglacial mélange rapidly down fjord. Rapid mélange motion continued for several minutes after the approximate 5-min duration of the capsize, and was accompanied by continued serac collapses along the newly exposed calving front. A second iceberg calved at 07:04:31 UTC; it rotated top-out from the terminus. This iceberg's volume was considerably smaller than the first, perhaps by more than a factor of three, and took only three minutes to capsize. The mélange maintained fast flow speeds for additional 3-5 min. Visually observable motion of the mélange ceased over the subsequent ten minutes. Altogether the multiple-iceberg event removed more than $0.5 \mathrm{~km}^{3}$ of ice from the glacier.

\section{Seismic Data From Calving Event}

[7] The calving event generated a broadband range of seismic frequencies (Figures 4 and 5). We focus on two distinct signals between 0.05 and $0.1 \mathrm{~Hz}(10-20 \mathrm{~s})$ with good signal-to-noise ratios. At stations WIND (4 km from calving location) and SJFD (247 km from calving location) these signals dominate the frequency content of the calving generated seismicity (note that the horizontal components of WIND exhibit a strong background noise at lower frequencies). At station ILULI (57 km from calving location), the $0.05-0.1 \mathrm{~Hz}$ signals are clearly visible, too. However, the dominating signal lies near $0.01 \mathrm{~Hz}$ and thus within the frequency range used in previous, global studies of glacial earthquakes (0.007-0.03 Hz) [Ekström et al., 2003, 2006; Tsai and Ekström, 2007; Tsai et al., 2008]. Nevertheless, the strong signal between 0.05 and $0.1 \mathrm{~Hz}$ is consistent with regional observations of previous glacial earthquakes, which tend to contain peak power in this frequency range (Figure 6).
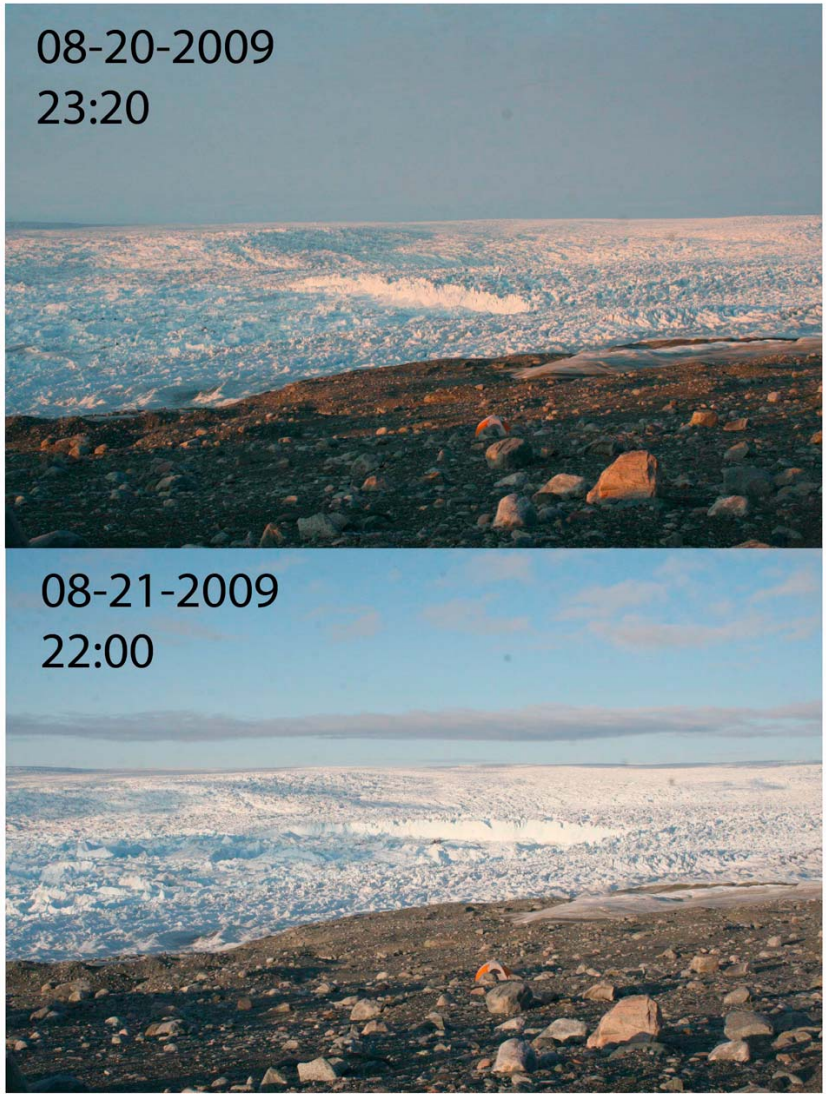

Figure 3. Two images of the time-lapse sequence (see Video S1 of the auxiliary material) of Jakobshavn Isbræ's calving front. The camera was collocated with the seismometer WIND (Figures 1 and 2). The images were taken approximately (top) $7.5 \mathrm{~h}$ before and (bottom) $13 \mathrm{~h}$ after the 21 August 2009, calving event. The ice cliff is about $100 \mathrm{~m}$ high. 


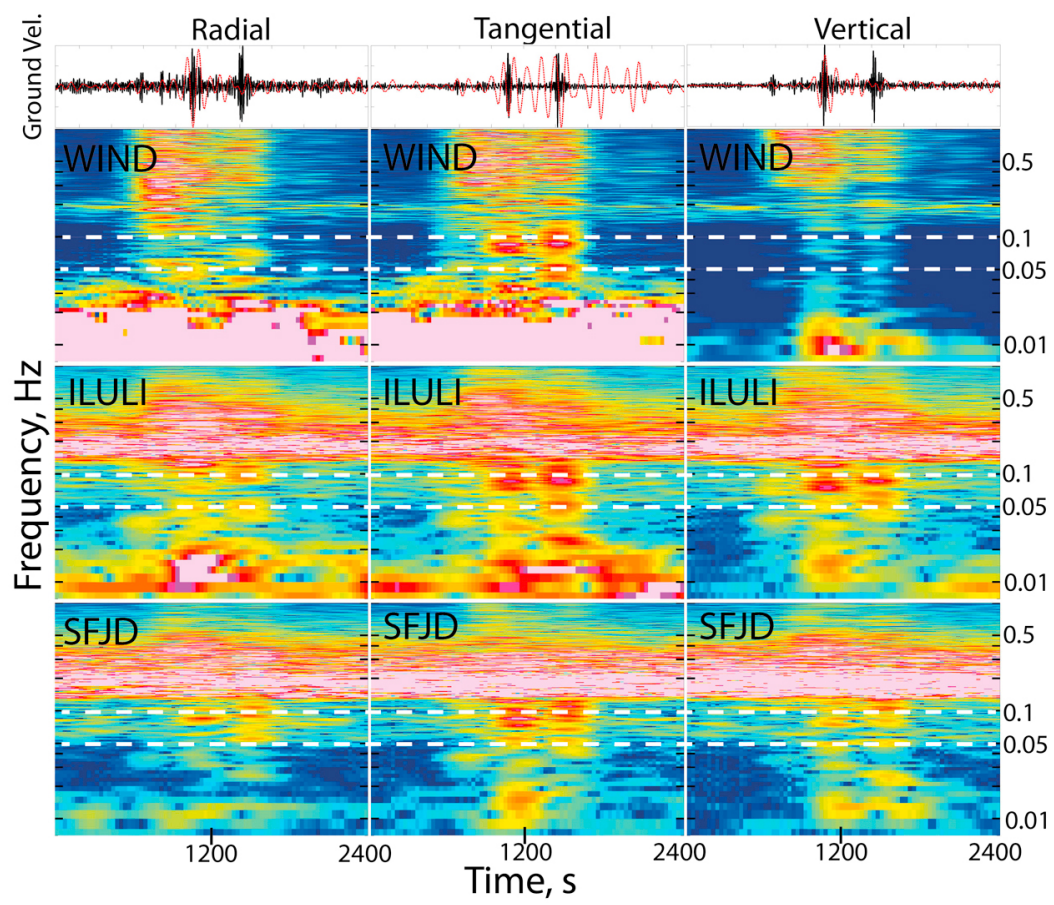

Figure 4. Spectrograms from stations WIND, ILULI and SFJD recorded during the calving event on 21 August 2009. All components belonging to the same station share the same color axes of the power spectral density. The white dashed lines indicate the bandpass $(0.05-0.1 \mathrm{~Hz})$ used in the full waveform inversion. On top we show the seismograms at ILULI, filtered between 0.05 and $0.1 \mathrm{~Hz}$ (black) and between 0.01 and $0.02 \mathrm{~Hz}$ (red).

[8] To create a record section (Figure 5 and Video S1 of the auxiliary material), we shifted all records backward by the travel time for Love or Rayleigh Waves to propagate from the source to the receiver, assuming velocities of 4.36 and $3.89 \mathrm{~km} / \mathrm{s}$, respectively. These velocities are approximate as they correspond to the group velocities at 50-s period used by Chen et al. [2011] to study Antarctic glacial earthquakes. The record section provides good synchronization between the seismograms and time-lapse imagery. At SUMG and KULLO (558 and $661 \mathrm{~km}$ from calving location, respectively) the $0.05-0.1 \mathrm{~Hz}$ signals misalign by over $20 \mathrm{~s}$ with respect to the other stations. This represents an error of more than $16 \%$ (1-2 cycles), which is likely related to changing material properties and the thick ice layer (in the case of SUMG), not addressed by the velocity model we use. These stations are not used in the inversion (section 5) as the seismic velocity model used in our waveform-modeling scheme is not suitable for such large epicentral distances. Rather we include SUMG and KULLO mainly to demonstrate extended signal propagation

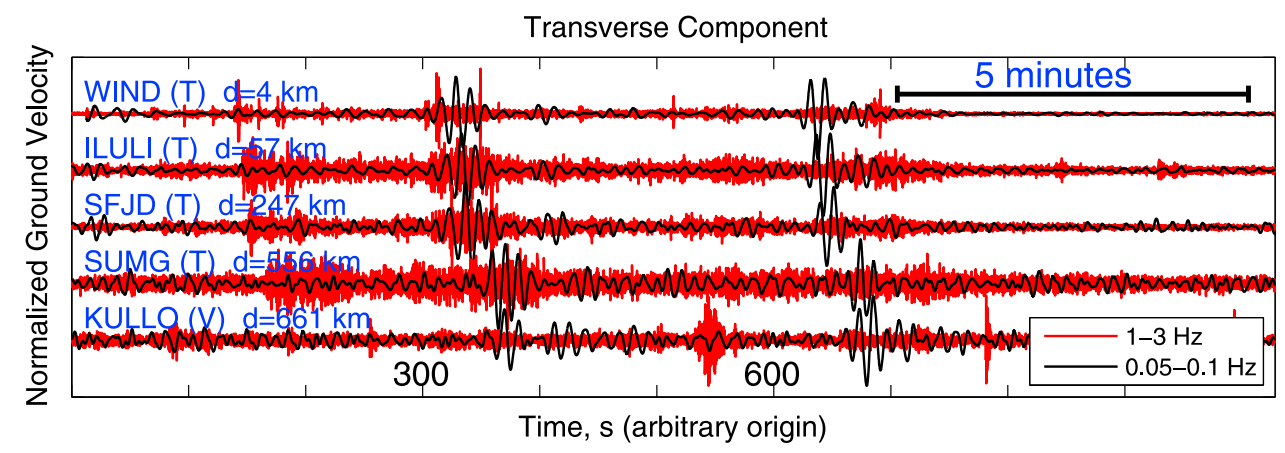

Figure 5. High frequency (1-3 Hz, red) and low frequency $(0.05-0.1 \mathrm{~Hz}$, black) seismograms recorded during the 21 August 2009 calving event. ' $T$ ' and ' $V$ ' stand for transverse and vertical components. Each seismogram was normalized to its maximum. The time-lapse footage (Video S1 of the auxiliary material) links the generation of the two low-frequency arrivals to iceberg capsizing. These arrivals do not necessarily coincide with bursts in high frequency signals generated by englacial fracturing, mélange movement and avalanching. Reduction velocities of 4.36 and $3.89 \mathrm{~km} / \mathrm{s}$ were applied to account for Love (transverse component) and Rayleigh (vertical component) wave travel times, respectively. 

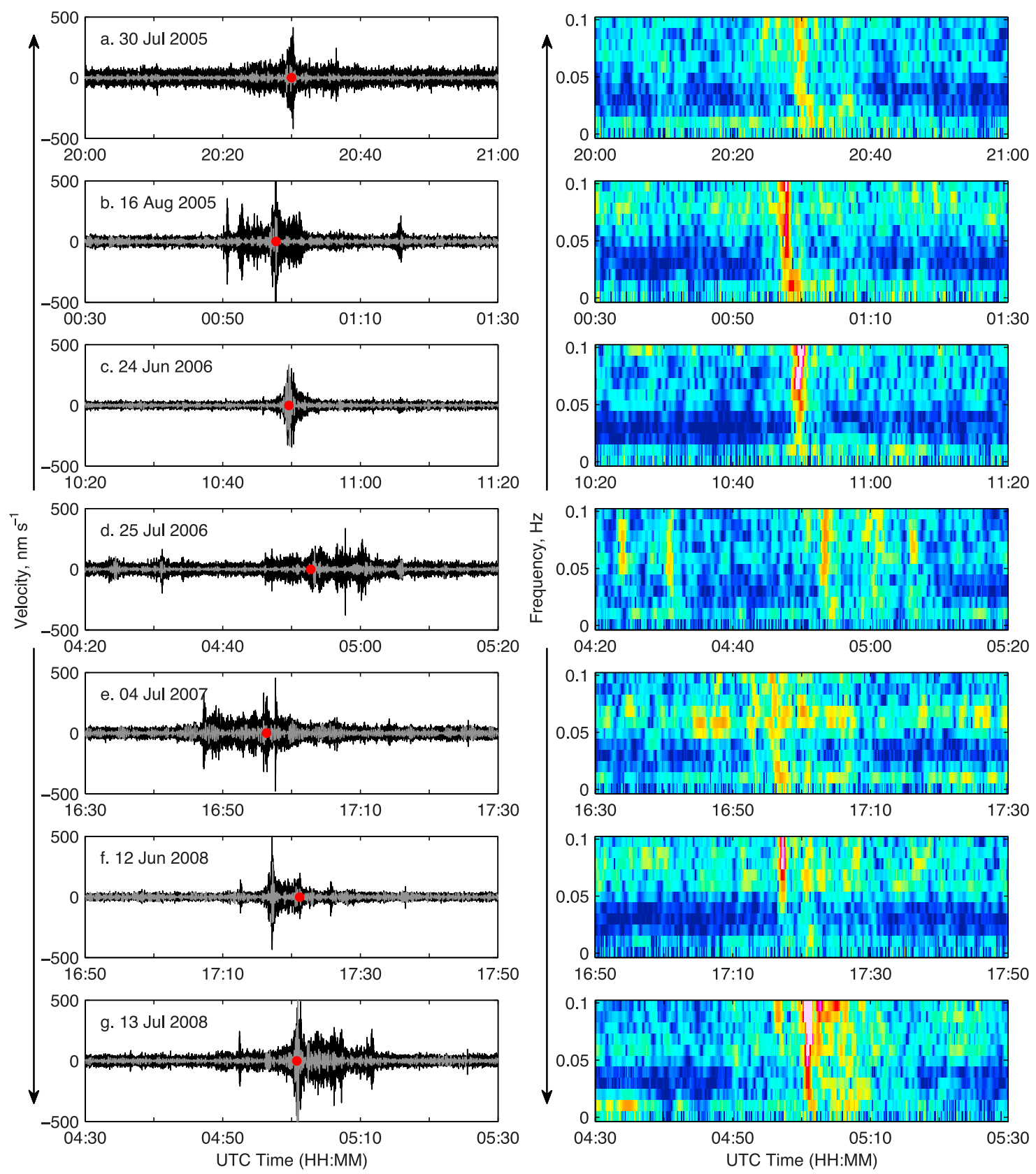

Figure 6. (left) Seismograms and (right) corresponding spectrograms of glacial earthquakes, recorded at station SFJD, that originated from Jakobshavn Isbræ between 2005 and 2008. The black and gray time series were bandpass-filtered between 1 and $3 \mathrm{~Hz}$ and $0.05-0.1 \mathrm{~Hz}$, respectively. The red dots mark origin times of glacial earthquakes (with addition of a source to receiver travel time of $62.5 \mathrm{~s}$ ) [Tsai and Ekström, 2007; Nettles and Ekström, 2010]. The glacial earthquakes occurred during calving events and contained peak power in the $0.05-0.1 \mathrm{~Hz}$ band.

characteristics. A propagation-corrected time-lapse movie (Video S1 of the auxiliary material) clearly associates the two $0.05-0.1 \mathrm{~Hz}$ seismic signals with the capsizing of two fullglacier-thickness icebergs. The signals were generated near the end of the icebergs' rotations and had similar amplitudes, despite large differences in iceberg size.

[9] In addition to the low-frequency energy considered here, the seismograms contain several peaks in highfrequency $(1-3 \mathrm{~Hz})$ energy (Figure 5). These peaks are recorded at most stations, including SUMG, and are associated with the initiation of mélange motion and with the calving and capsizing of the two large icebergs that produced the low-frequency signals [see also Amundson et al., 2010]. The first, and larger, of the two icebergs generated a higher amplitude peak in the $1-3 \mathrm{~Hz}$ band.

[10] Finally, we note that the spectrograms (Figure 4) exhibit station-specific background signals, which are not directly related to the mechanics of iceberg detachment. At 
Table 1. The 1D Crustal and Upper Mantle Velocity Model Beneath the Study Site Showing P- and S-Velocities ( $\mathrm{v}_{\mathrm{p}}$ and $\left.\mathrm{v}_{\mathrm{s}}\right)$, Density $(\rho)$ and Q Values for P- and S-Waves

\begin{tabular}{ccccccc}
\hline $\begin{array}{c}\text { Depth } \\
\text { Range }(\mathrm{km})\end{array}$ & $\begin{array}{c}\text { Thickness } \\
(\mathrm{km})\end{array}$ & $\mathrm{v}_{\mathrm{p}}(\mathrm{km} / \mathrm{s})$ & $\mathrm{v}_{\mathrm{s}}(\mathrm{km} / \mathrm{s})$ & $\rho\left(\mathrm{g} / \mathrm{cm}^{3}\right)$ & $\mathrm{Q}_{\mathrm{p}}$ & $\mathrm{Q}_{\mathrm{s}}$ \\
\hline $0-13$ & 13 & 6.2 & 3.6 & 2.8 & 600 & 300 \\
$13-25$ & 12 & 6.4 & 3.6 & 2.85 & 600 & 300 \\
$25-37$ & 12 & 6.7 & 3.8 & 2.95 & 600 & 300 \\
$37-\infty$ & $\infty$ & 8.2 & 4.7 & 3.4 & 600 & 300 \\
\hline
\end{tabular}

stations ILULI and SFJD, the spectrograms contain maximum power between 0.1 and $0.5 \mathrm{~Hz}$. This includes the frequency range of the double-frequency microseism peak [Longuet-Higgins, 1950], generated by standing gravity waves in the ocean. This noise source tends to be particularly strong in coastal regions [McNamara and Buland, 2004]. On the other hand, the mélange cover inside of Ilulissat Icefjord likely damps ocean waves and thus the energy of the double-frequency microseism peak recorded at WIND. A similar effect has been observed for sea ice cover [Grob et al., 2011; Tsai and McNamara, 2011].

\section{Full Waveform Modeling of Seismic Data}

[11] We performed full waveform modeling to characterize the sources of the low-frequency signals generated during the calving event (Figures 4 and 5 and section 4). Successful modeling requires knowledge about the source location, the Earth's seismic velocity structure between the source and station, and the character of the source time function. High-rate time-lapse photography (Video S1 of the auxiliary material) of the calving event suggests that the lowfrequency signals were generated by icebergs colliding with the glacier terminus. We therefore constrained the source location by comparing LANDSAT images acquired before and after the calving event (Figure 2) to determine the central location of the calving event. This is a simplification because the two icebergs did not calve from the exact same location. However, the resulting horizontal uncertainty is less than $1 \mathrm{~km}$. A shallow source depth of $400 \mathrm{~m}$ was also prescribed, given that the seismic source was connected to glaciological processes. Additionally, we only analyzed data from stations WIND, ILULI, and SFJD, because the proximity of these stations to the glacier's terminus allowed us to use a one-dimensional, depth-dependent (four layers) seismic velocity model (crust2.0) of the Earth's crust and upper mantle (see Table 1; Bassin et al. [2000]; http://igppweb. ucsd.edu/ gabi/crust2.html). Finally, the source time function was adjusted to find the best fit between observed and synthetic seismograms.

\subsection{Seismic Data Pre-processing}

[12] After removing the instrument response we integrated velocity seismograms to ground displacement and rotated into source-station coordinates (radial, transverse, and vertical). The seismograms were then bandpass-filtered between 0.05 and $0.1 \mathrm{~Hz}$ (2-pole, zero phase Butterworth filter), which optimized the signal-to-noise ratio (Figure 4), and interpolated to a 1-s sampling interval.

\subsection{Inversion Scheme}

[13] Following the expectation that the seismic signals were generated by iceberg collisions, we chose to model the source using a single force mechanism. This assumption is consistent with previous studies of glacial earthquakes [Ekström et al., 2003, 2006; Tsai and Ekström, 2007; Tsai et al., 2008], but differs from more common force couples ('double-couples') used in tectonic source models that describe shear dislocations [e.g., Aki and Richards, 2002].

[14] In our inversion we first generate synthetic seismograms for each station by calculating the theoretical elastic response (Green's functions) to three orthogonal single forces (pointing north, east, and vertical) at the prescribed location of the calving event. The Green's Functions are calculated using a numerical implementation of the propagatormatrix approach (with the fk3.0 software package; Zhu and Rivera [2002]; http://www.eas.slu.edu/People/LZhu/downloads/ fk3.0.tar) at a sampling interval of $0.1 \mathrm{~s}$. The results are interpolated to a 1-s sampling interval to match the data sampling interval, convolved with a source time function (section 5.3), and then filtered between 0.05 and $0.1 \mathrm{~Hz}$. Due to uncertainty in the source time and seismic velocities, we cannot expect the synthetic time series to perfectly align with the observed seismograms. We therefore manually adjust the time lag between data and synthetics ( $\tau$-value) to maximize fit quality; the adjustment is done for each station individually [e.g., Clinton et al., 2006]. Finally, the best fit magnitude of the source time function is determined in a least squares sense, and the fit quality is quantified using variance reduction [e.g., Dreger, 2003]. This gives the force vector that best represents the source of the low-frequency seismic signals.

\subsection{Source Time Function}

[15] We tested three different source time functions in our waveform modeling: a delta function, a boxcar function, and a centroid single force (CSF) [see Kawakatsu, 1989; Tsai and Ekström, 2007]. The CSF source time function consists of two consecutive boxcars with equal magnitude but opposite sign (Figure 7). The delta function was implemented with a 1-s force impulse, and the duration of the boxcar and symmetric CSF functions were varied from

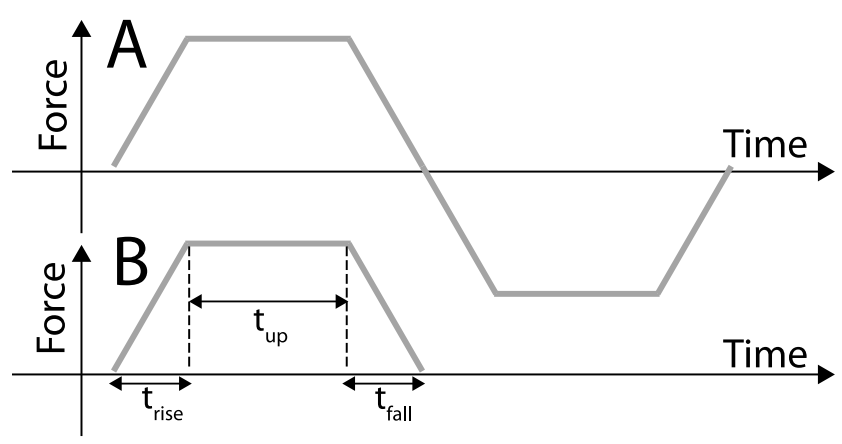

Figure 7. Finite CSF (A) and boxcar (B) source time functions. Both are made up of $t_{\text {rise }}, t_{\text {fall }}$ and $t_{\text {up. The CSF func- }}$ tion consists of two consecutive boxcar functions with amplitudes that are equal in magnitude but opposite in sign. We fix $t_{\text {fall }}$ and $t_{\text {rise }}$ to $1 \mathrm{~s}$ and vary $t_{\text {up }}$ as described in the text. A delta function impulse is the same as a boxcar source time function with zero $t_{u p}$. 


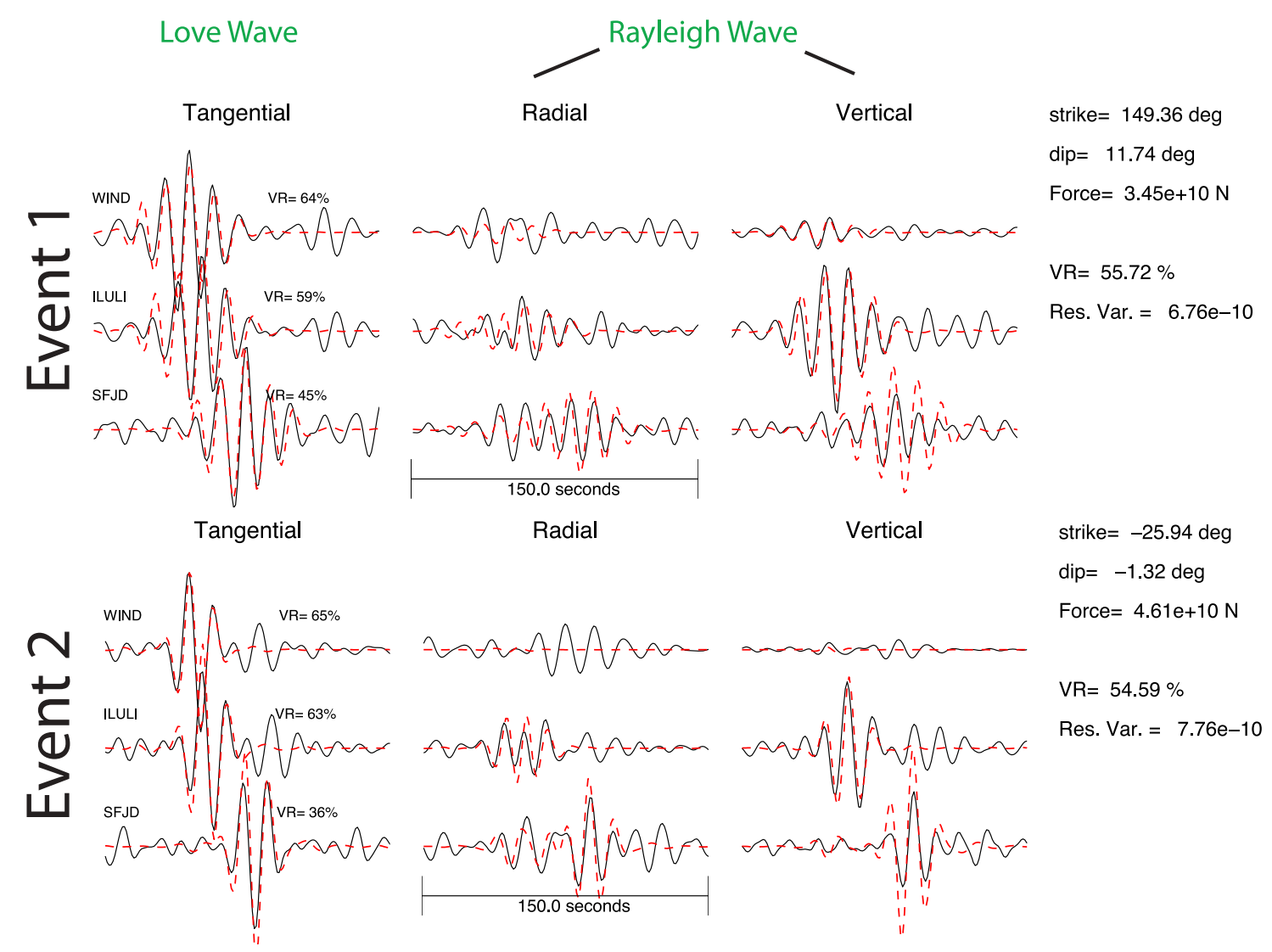

Figure 8. Ground displacement waveform fits for the low frequency seismic signals, referred to as (top) event 1 and (bottom) event 2, using displacement seismograms at WIND, ILULI and SFJD, filtered between 0.05 and $0.1 \mathrm{~Hz}$. The fit is based on $38 \mathrm{~s}$ (event 1) and $8 \mathrm{~s}$ (event 2) long CSF source time functions. For each station, data and fit time series share the same vertical scale. Both Love and Rayleigh waves are satisfactorily fit for both events. The calculated CSF single forces are nearly horizontal.

4-50 s; the 50-s duration matches the best fit results from previous studies of glacial earthquakes [e.g., Tsai et al., 2008]. These force histories represent varying levels of physical complexity, where delta functions represent brief collisions between an iceberg and the glacier's terminus and boxcar and CSF functions may better represent sustained collisions. The delta and boxcar functions can be viewed as transferring momentum to the proglacial water. The more complex CSF history, on the other hand, conserves momentum along the contact plane. In case of the landslide model, for example, the CSF history represents the equal but opposite forces during the landslide detachment and its subsequent slowdown. Consequently, the success of the CSF function in waveform modeling of glacial earthquakes led to the initial interpretation that glacier-sliding episodes cause the seismic events [e.g., Ekström et al., 2003]. In the context of iceberg calving, the CSF source time function is more difficult to interpret, but may represent the dragging of two surfaces across each other during iceberg detachment and/or collision.

\section{Model Results, Sensitivity, and Uncertainty}

[16] The best fit results of the two seismic signals were achieved using symmetric CSF source time functions with total durations of $38 \mathrm{~s}$ and $8 \mathrm{~s}$ and force amplitudes of $3.5 \times$
$10^{10} \mathrm{~N}$ and $4.6 \times 10^{10} \mathrm{~N}$, respectively (Figure 8). These functions correspond to magnitudes of $1.2 \times 10^{13} \mathrm{~kg} \mathrm{~m}$ and $7.4 \times 10^{11} \mathrm{~kg} \mathrm{~m}$. Both Love (tangential component) and Rayleigh waves (radial and vertical components) were satisfactorily fit, although for both signals the misfit was highest for the Rayleigh wave recorded at far-field station SFJD. The variance reductions of the synthetic seismograms were $56 \%$ and $55 \%$.

[17] The fit quality decreased only slightly when using boxcar or 1-s force impulse functions. For example, for the force impulse functions the variance reductions were $50 \%$ and $54 \%$ (Figure 9). The impulse functions had peak forces of $1.6 \times 10^{11} \mathrm{~N}$ and $2.0 \times 10^{11} \mathrm{~N}$, which yields magnitudes of $4.0 \times 10^{10} \mathrm{~kg} \mathrm{~m}$ and $5.0 \times 10^{10} \mathrm{~kg} \mathrm{~m}$.

[18] For both seismic signals, the 1-s impulse source time functions yielded force vectors that were roughly horizontal and pointed up-glacier (with a possible $180^{\circ}$ ambiguity) (Figures 9 and 2). The forces of the CSF waveform fit are also nearly horizontal, but their directions approximately reversed. The $180^{\circ}$ ambiguity is an artifact of the inversion, because a half wavelength shift between the synthetic and observed seismograms $(\tau)$ may not significantly alter the fit quality but reverses the direction of the single force source [see also Tsai and Ekström, 2007]. For example, Figure 10 shows that a $\tau$-shift of about $6 \mathrm{~s}$ reduces the variance 
Love Wave

Tangential

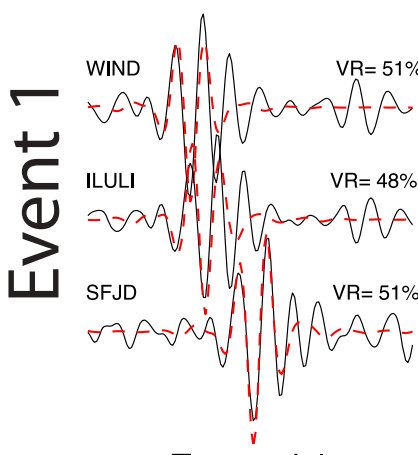

Tangential

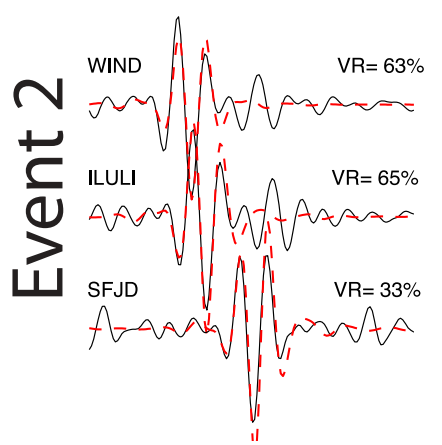

Rayleigh Wave

Radial

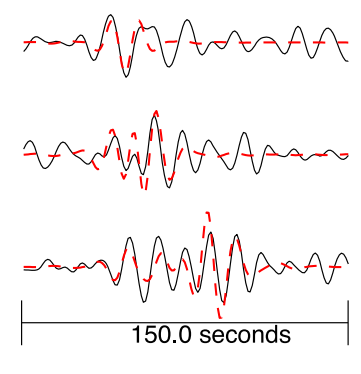

Radial
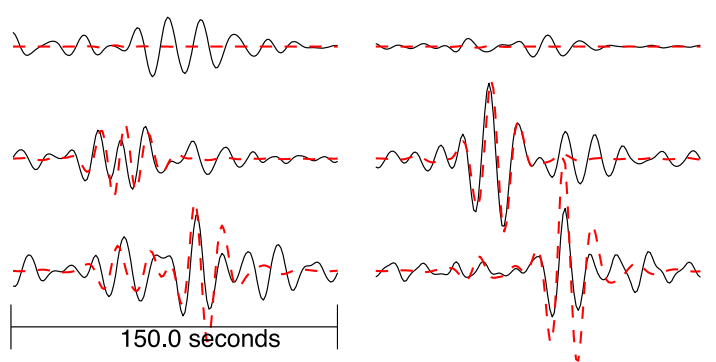

strike $=143.23 \mathrm{deg}$

$\mathrm{dip}=13.83 \mathrm{deg}$

Force $=1.61 \mathrm{e}+11 \mathrm{~N}$

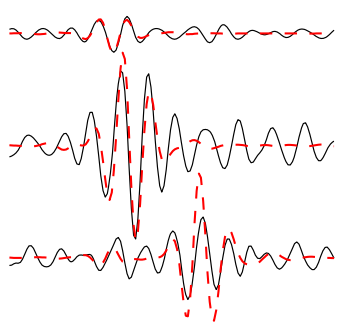

$\mathrm{VR}=50.04 \%$

Res. Var. $=9.01 \mathrm{e}-10$
Vertical

strike $=152.89 \mathrm{deg}$

$\mathrm{dip}=0.47 \mathrm{deg}$

Force $=2.00 \mathrm{e}+11 \mathrm{~N}$

$\mathrm{VR}=53.50 \%$

Res. Var. $=8.15 \mathrm{e}-10$

Figure 9. Same as Figure 8 except using a $1 \mathrm{~s}$ impulse as a source time function. The calculated single forces are nearly horizontal and point in roughly the same direction.

reduction by just a few percent (red curve) but changes the strike by about $180^{\circ}$ (green curve). We therefore do not reject the possibility that the strike values are $180^{\circ}$ out of phase.

[19] To test our results, we explored fit sensitivity of the 1-s force impulse inversion with jackknife tests [e.g., Swan and Sandilands, 1995] by removing each of the station records one at a time and/or replacing its record with another record. These perturbations changed the calculated strike and dip values by less than $\pm 3^{\circ}$ and $\pm 6^{\circ}$, respectively. We also investigated how errors in source depths and epicentral location affected the inversion results by displacing the source $1.0 \mathrm{~km}$ horizontally and increasing the depth to $800 \mathrm{~m}$. The calculated strike and dip values changed by less than $5^{\circ}$. For all of these experiments, the force magnitudes changed by less than $25 \%$.

[20] Although the waveform inversions used only three stations, these sensitivity tests indicate that the main features of our results are robust: namely, that the low-frequency seismic signals were generated by near-horizontal single forces aligned parallel to the glacier flow direction (Figures 9 and 2).

\section{Discussion and Conclusions}

[21] We have observed regionally recorded, low-frequency $(<0.1 \mathrm{~Hz})$ seismic signals associated with the calving and capsizing of two full-glacier-thickness icebergs at
Jakobshavn Isbræ. The signals had high power and maximum signal-to-noise ratios between 0.05 and $0.1 \mathrm{~Hz}$. Furthermore, the signals were generated as the icebergs were finishing capsizing, coinciding with the maximum kinetic energy of the icebergs [see also Burton et al., 2012]. Waveform inversions indicate that the source time functions can be adequately described by horizontal delta-impulse functions for single forces that point nearly parallel to the glacier flow axis. Using boxcar or CSF source time functions with durations of $10-20 \mathrm{~s}$ provides only a marginal improvement to the fit between synthetic and observed seismograms. However, these source time functions can lead to substantially different interpretations of the physical processes involved in calving.

[22] The observations and waveform inversions presented here are consistent with previous studies of teleseismic glacial earthquakes, with two exceptions. First, we have analyzed data from a higher bandpass than has been used in previous studies [Tsai and Ekström, 2007]. Analysis of published glacial earthquakes [Tsai and Ekström, 2007; Nettles and Ekström, 2010] indicates that those events, when recorded regionally, also had high power and signal-to-noise ratios in the $0.05-0.1 \mathrm{~Hz}$ band (Figure 6). Energy in this band is likely attenuated and therefore undetectable at global distances. Second, waveform inversions on global seismic data yield considerably longer force histories (typically about $50 \mathrm{~s}$ ) than was required here. This may in part be due to the fact that we analyzed a higher frequency band. 


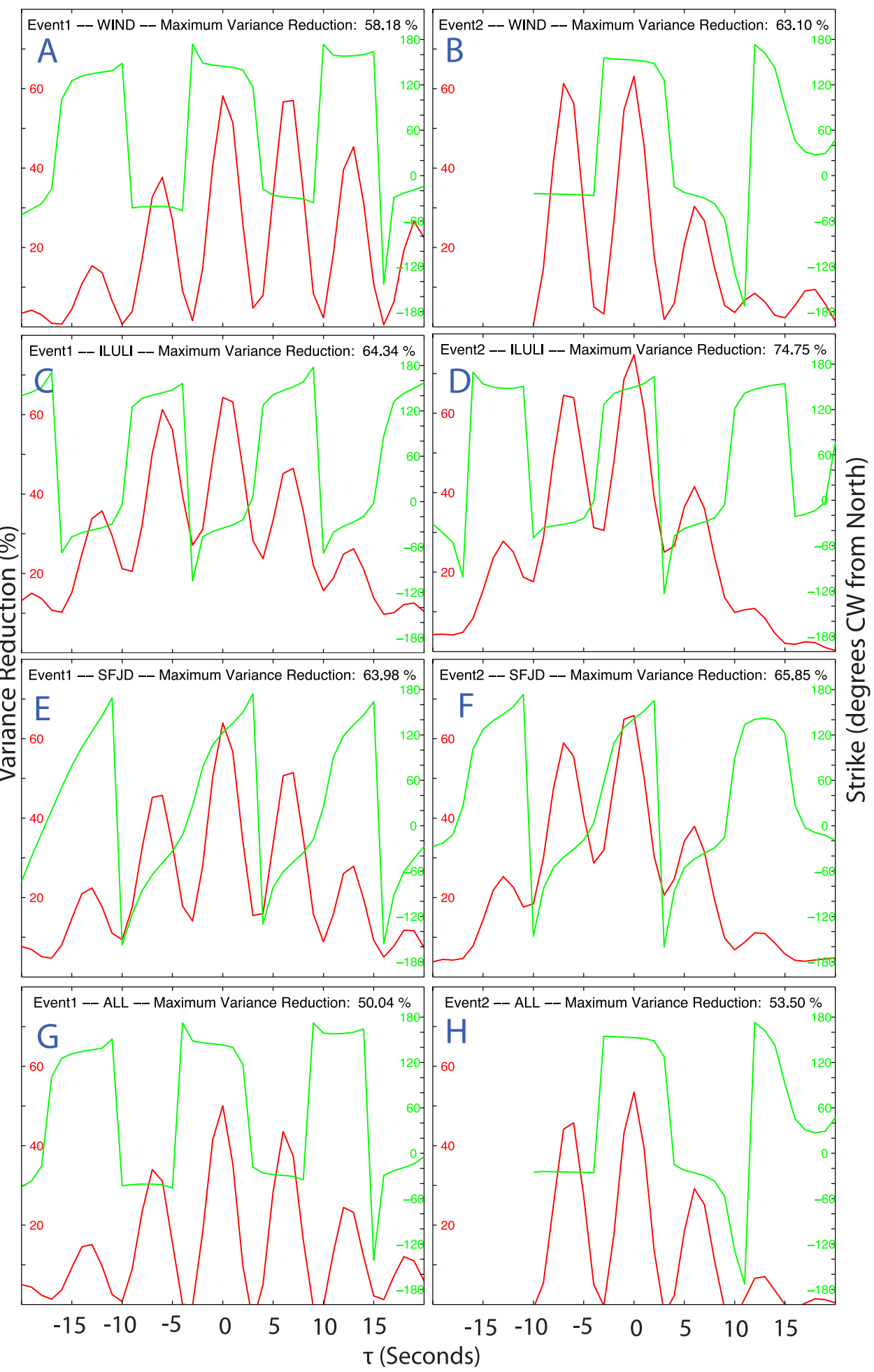

Figure 10. Variance reduction (red) and force strike (green) for $1 \mathrm{~s}$-force impulse inversions as a function of $\tau$ (time shift between data and synthetic time series). (a-f) The results of single station inversion runs, and $(\mathrm{g}-\mathrm{h})$ the results using all stations. The origin of the $x$ axis was chosen such that $\tau=0$ corresponds to the value used in the inversion runs shown in Figure 9. Figures 10a, 10c, 10e and $10 \mathrm{~g}$ depict the results for the first low-frequency arrival (event 1); Figures 10b, 10d, 10f and 10g depict the results for the second low-frequency arrival (event 2). For inversions of event 2 involving station WIND (Figures 10a, 10b, $10 \mathrm{~g}$ and $10 \mathrm{~h}$ ), the negative $\tau$ values were limited to -10 , because the signal was too close to the beginning of the time series used in the inversion. 
Nonetheless, we take this as further testament that inversions of waveforms generated by single-force mechanisms are insensitive to the choice of source time function [see also Tsai et al., 2008]; thus the best fit durations and associated glacial earthquake magnitudes (twice time-integrated force histories), should be interpreted with caution. A comparison of glacial earthquake spectra with theoretical spectra of impulse and CSF functions may further constrain source time functions. However, low signal-to-noise ratios and various concurrent seismic sources related to glaciological and oceanic processes (Figure 4) inhibit such an analysis.

[23] Finally, our results support the hypothesis that glacial earthquakes are generated by icebergs colliding with a glacier's terminus during calving events [Tsai et al., 2008], and that these signals may therefore be indicative of calving style [Joughin et al., 2008a; Amundson et al., 2008]. Interestingly, the $0.05-0.1 \mathrm{~Hz}$ energy is generated at the end of capsizing when the iceberg no longer undergoes angular acceleration. This indicates that these seismic signals are not associated with iceberg acceleration away from the terminus. There remain open questions about the seismic energy generation. It is somewhat surprising that the two capsizing icebergs generate almost parallel single forces (indicated by the force impulse inversion, Figures 2 and 9), although the first iceberg detaches 'bottom-out', whereas the second iceberg detaches 'top-out'. However, the $180^{\circ}$ strike ambiguities inherent to the presented regional and previously performed global [Tsai and Ekström, 2007] full waveform inversions inhibit further interpretation of the force directions. Furthermore, it is not clear why iceberg collision occurs at the end of capsizing, as the results indicate. Laboratory studies of capsizing icebergs together with seismic waveform modeling [Burton et al., 2012; Amundson et al., 2012] will likely help resolve these issues.

[24] The apparent insensitivity of the waveform inversions to the duration of the source time function indicates that calving mass losses are difficult to estimate based on seismic signals, alone. Furthermore, our seismic inversions demonstrate that seismic magnitude does not scale with iceberg volume in a simple manner. This may be due to nonlinear hydrodynamic drag forces [Burton et al., 2012; Amundson et al., 2012] and/or resistive forces from a proglacial ice mélange [Tsai et al., 2008], both of which strongly influence iceberg-capsize and associated iceberg-terminus contact forces. Consequently, when analyzed in conjunction with other field observations, low-frequency seismic signals may give insights into iceberg-capsize dynamics including hydrodynamic drag forces.

[25] Acknowledgments. We acknowledge the contributions of Bryn Hubbard, Göran Ekström, Trine Dahl-Jensen, Jake Walter, Matt Haney, and an anonymous reviewer to the improvement of this manuscript. This work also benefited from discussions with Victor Tsai, John Clinton, and Martin Lüthi. Gabi Laske assisted with the crust 2.0 model. The inversion

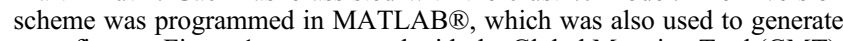
most figures. Figure 1 was prepared with the Global Mapping Tool (GMT). Seismograms were processed with MATLAB ${ }^{R}$ and the Seismic Analysis Code (SAC) [Goldstein et al., 2003]. Funding was provided by NASA's Cryospheric Sciences Program (NNG06GB49G and NNX08AN74G) and the U.S. National Science Foundation (AEC0909333, ANT0739769, ANT0944193, and IPY0732726). The USGS Climate and Land Use Change program supported this work by paying the salary of S. O'Neel. Seismic stations ILULI, KULLO, and NUUG are operated by ETH Zurich; station SFJD is operated by IRIS, GFZ, and GEUS. The data were collected and distributed by the Greenland Ice Sheet Monitoring Network (GLISN) federation and its members.

\section{References}

Aki, K., and P. G. Richards (2002), Quantitative Seismology, 2nd ed., Univ. Sci. Books, Sausalito, Calif.

Amundson, J. M., M. Truffer, M. P. Lüthi, M. Fahnestock, M. West, and R. J. Motyka (2008), Glacier, fjord, and seismic response to recent large calving events, Jakobshavn Isbrae, Greenland, Geophys. Res. Lett., 35, L22501, doi:10.1029/2008GL035281.

Amundson, J. M., M. Fahnestock, M. Truffer, J. Brown, M. P. Lüthi, and R. J. Motyka (2010), Ice mélange dynamics and implications for terminus stability, Jaobshavn Isbrae, Greenland, J. Geophys. Res., 115, F01005, doi:10.1029/2009JF001405

Amundson, J. M., J. C. Burton, and S. Correa-Legisos (2012), Hydrodynamic consequences for seismic signals generated by iceberg collisions, Ann. Glaciol., in press.

Bassin, C., G. Laske, and G. Masters, (2000), The current limits of resolution for surface wave tomography in North America, Eos Trans. $A G U, 81(48)$, Fall Meet. Suppl., Abstract S12A-03.

Burton, J. C., J. M. Amundson, D. S. Abbot, A. Boghosian, L. M. Cathles, S. Correa-Legisos, K. N. Darnell, N. Guttenberg, D. M. Holland, and D. R. MacAyeal (2012), Laboratory investigations of iceberg-capsize dynamics, energy dissipation and tsunamigenesis, J. Geophys. Res. 117, F01007, doi:10.1029/2011JF002055.

Chen, X., P. M. Shearer, F. Walter, and H. A. Fricker (2011), Seventeen Antarctic seismic events detected by global surface waves and a possible link to calving events from satellite images, J. Geophys. Res., 116, B06311, doi:10.1029/2011JB008262.

Clinton, J. F., E. Hauksson, and K. Solanki (2006), An evaluation of the SCSN moment tensor solutions: Robustness of the $\mathrm{M}_{\mathrm{W}}$ magnitude scale, style of faulting and automation of the method, Bull. Seismol. Soc. Am., 96(5), 1689-1705, doi:10.1785/0120050241.

Dahl-Jensen, T., T. B. Larsen, P. H. Voss, and the GLISN group, (2010), Greenland ice sheet monitoring network (GLISN): A seismological approach, Geol. Surv. Denmark Greenl. Bull., 20, 55-58.

Dreger, D. S. (2003), TDMT_INV: Time domain seismic moment tensor inversion, in International Handbook of Earthquake and Engineering Seismology, edited by W. H. K. Lee et al., Int. Geophys., 81, 1627, doi:10.1016/S0074-6142(03)80290-5

Ekström, G., M. Nettles, and G. A. Abers (2003), Glacial earthquakes, Science, 302(5645), 622-624, doi:10.1126/science.1088057.

Ekström, G., M. Nettles, and V. C. Tsai (2006), Seasonality and increasing frequency of Greenland glacial earthquakes, Science, 311, 1756-1758, doi:10.1126/science.1122112

Goldstein, P., D. Dodge, M. Firpo, and L. Minner (2003), SAC2000: Signal processing and analysis tools for seismologists and engineers, Int. Geophys., 81, 1613-1614, doi:10.1016/S0074-6142(03)80284-X.

Grob, M., A. Maggi, and E. Stutzmann (2011), Observations of the seasonality of the Antarctic microseismic signal, and its association to sea ice variability, Geophys. Res. Lett., 38, L11302, doi:10.1029/2011GL047525.

Joughin, I., I. Howat, R. B. Alley, G. Ekström, M. Fahnestock, T. Moon, M. Nettles, M. Truffer, and V. Tsai (2008a), Ice-front variation and tidewater behavior on Helheim and Kangerdlugssuaq glaciers, Greenland, J. Geophys. Res., 113, F01004, doi:10.1029/2007JF000837.

Joughin, I., I. M. Howat, M. Fahnestock, B. Smith, W. Krabillll, R. B. Alley, H. Stern, and M. Truffer (2008b), Continued evolution of Jakobshavn Isbræ following its rapid speedup, J. Geophys. Res., 113, F04006, doi:10.1029/2008JF001023.

Kawakatsu, H. (1989), Centroid single force inversion of seismic waves generated by landslides, J. Geophys. Res., 94(B9), 12,363-12,374, doi:10.1029/JB094iB09p12363.

Longuet-Higgins, M. S. (1950), A theory of the origin of microseisms, Philos. Trans. R. Soc. A, 243, 1-35, doi:10.1098/rsta.1950.0012.

Luckman, A., and T. Murray (2005), Seasonal variation in velocity before retreat of Jakobshavn Isbræ, Greenland, Geophys. Res. Lett., 32, L08501, doi:10.1029/2005GL022519.

Lüthi, M. P. (2009), Terminus geometry as main control on outlet glacier velocity, Geophys. Res. Abstr., 11, 6862.

McNamara, D. E., and R. P. Buland (2004), Ambient noise levels in the continental United States, Bull. Seismol. Soc. Am., 94(4), 1517-1527, doi: $10.1785 / 012003001$.

Meier, M. F., M. B. Dyurgerov, U. K. Rick, S. O’Neel, W. T. Pfeffer, R. S. Anderson, S. P. Anderson, and A. F. Glazovsky (2007), Glaciers dominate eustatic sea-level rise in the 21 st century, Science, 317(1064), 1064-1067, doi:10.1126/science.1143906.

Nettles, M., and G. Ekström (2010), Glacial earthquakes in Greenland and Antarctica, Annu. Rev. Earth Planet. Sci., 38, 467-491, doi:10.1146/ annurev-earth-040809-152414.

Nettles, M., et al. (2008), Step-wise changes in glacier flow speed coincide with calving and glacial earthquakes at Helheim Glacier, Greenland, Geophys. Res. Lett., 35, L24503, doi:10.1029/2008GL036127. 
O’Neel, S., H. P. Marshall, D. E. McNamara, and W. T. Pfeffer (2007), Seismic detection and analysis of icequakes at Columbia Glacier, Alaska, J. Geophys. Res., 112, F03S23, doi:10.1029/2006JF000595.

O’Neel, S., C. Larsen, N. Rupert, and R. Hansen (2010), Iceberg calving as a primary source of regional-scale glacier-generated seismicity in the St Elias Mountains, Alaska, J. Geophys. Res., 115, F04034, doi:10.1029/ 2009JF001598.

Qamar, A. (1988), Calving icebergs: A source of low-frequency seismic signals from Columbia Glacier, Alaska, J. Geophys. Res., 93, 6615-6623, doi:10.1029/JB093iB06p06615.

Rignot, E., J. L. Bamber, M. R. van den Broeke, C. Davies, Y. Li, W. J. van de Berg, and E. van Meigaard (2008), Recent Antarctic ice mass loss from radar interferometry and regional climate modeling, Nat. Geosci., 1 , 106-110, doi:10.1038/ngeo102.

Swan, A. R. H., and M. Sandilands (1995), Introduction to Geological Dato Analysis, Blackwell Sci., Malden, Mass.

Tsai, V. C., and G. Ekström (2007), Analysis of glacial earthquakes, J. Geophys. Res., 112, F03S22, doi:10.1029/2006JF000596.

Tsai, V. C., and D. E. McNamara (2011), Quantifying the influence of sea ice on ocean microseism using observations from the Bering Sea, Alaska, Geophys. Res. Lett., 38, L22502, doi:10.1029/2011GL049791.

Tsai, V. C., J. R. Rice, and M. Fahnestock (2008), Possible mechanisms for glacial earthquakes, J. Geophys. Res., 113, F03014, doi:10.1029/ 2007JF000944. van den Broeke, M., J. Bamber, J. Ettema, E. Rignot, E. Schrama, W. J. van de Berg, E. van Meijgaard, I. Velicogna, and B. Wouters (2009), Partitioning recent Greenland mass loss, Science, 326(5955), 984-986, doi:10.1126/science. 1178176

Walter, F., S. O’Neel, D. McNamara, W. T. Pfeffer, J. N. Bassis, and H. A. Fricker (2010), Iceberg calving during transition from grounded to floating ice: Columbia Glacier, Alaska, Geophys. Res. Lett., 37, L15501, doi:10.1029/2010GL043201.

Zhu, L., and L. Rivera (2002), A note on the dynamic and static displacements from a point source in multilayered media, Geophys. J. Int., 148(3), 619-627, doi:10.1046/j.1365-246X.2002.01610.x

J. M. Amundson, Department of Geophysical Sciences, University of Chicago, Chicago, IL 60637, USA.

M. Fahnestock, Institute for the Study of Earth, Oceans, and Space, University of New Hampshire, Durham, NH 03824, USA.

H. A. Fricker and F. Walter, Institute of Geophysics and Planetary Physics, Scripps Institution of Oceanography, University of California, San Diego, La Jolla, CA 92093, USA. (walter@vaw.baug.ethz.ch)

S. O’Neel, Alaska Science Center, U.S. Geological Survey, 4210 University Dr., Anchorage, AK 99508, USA.

M. Truffer, Geophysical Institute, University of Alaska Fairbanks, Fairbanks, AK 99775, USA. 